\title{
Endoscopic dacryocystorhinostomy with and without mucosal flap-is there any difference?
}

\author{
Ofira Zloto ${ }^{1,2} \cdot$ Tal Koval $^{1,2} \cdot$ Arkadi Yakirevich $^{2,3} \cdot$ Guy J Ben Simon ${ }^{1,2} \cdot$ Alon Weissman $^{1,2} \cdot$ Elad Ben Artsi $^{1,2}$. \\ Joseph Ben Shoshan ${ }^{2,3} \cdot$ Ayelet Priel ${ }^{1,2}$
}

Received: 2 August 2019 / Revised: 16 September 2019 / Accepted: 27 September 2019 / Published online: 25 November 2019

(c) The Author(s), under exclusive licence to The Royal College of Ophthalmologists 2019

\begin{abstract}
Background The nasal mucosa is sacrificed in conventional endoscopic dacryocystorhinostomies (EDCRs). Some surgeons, however, modify the technique by elevating a mucosal flap prior to creating the osteotomy with the aim of preserving the mucosa. To our knowledge, no clear-cut benefit of a mucosal flap has been established. The aim of this study is to examine the differences in surgical techniques and success rates of EDCRs with and without mucosal flap preservation.

Methods We carried out a medical record review of all patients who underwent primary EDCR at the Goldschleger Eye Institute from October 2009 to October 2017. The following data were retrieved from the medical database and analyzed: patient demographics (age at diagnosis and gender), medical history, examination findings, surgical details, postoperative success, complications, and follow-up.

Results A total of 107 patients who underwent 117 EDCRs participated in the study. Fifty-one patients comprised the group without a mucosal flap and 56 patients comprised the group with mucosal flap preservation. The medical history, presenting complaints, and preoperative examination findings were similar for both groups. The surgical success rate was not significantly different between the groups ( $82.1 \%$ without flap vs. $86.8 \%$ with flap, $P=0.478$, Chi-square).

Conclusion The findings of this comparison of EDCRs with and without mucosal flap preservation in a large patient population revealed no differences in surgical success or complications rates between the two procedures and, therefore, no benefit for adding flap preservation to conventional EDCRs.
\end{abstract}

\section{Introduction}

Dacryocystorhinostomy (DCR) is a surgical procedure performed to resolve epiphora due to nasolacrimal duct obstruction (NLDO) of either an anatomical or functional origin [1]. The aim of the DCR procedure is to create a connection between the lacrimal sac and the nasal cavity in order to provide a direct bypass of the blocked or narrowed nasolacrimal duct. The original endonasal (nonendoscopic) approach was first described in 1893 by Caldwell [1], and

Ofira Zloto

ozloto@gmail.com

1 Goldschleger Eye Institute, The Chaim Sheba Medical Center, Tel Hashomer, Israel

2 Sackler Faculty of Medicine, Tel Aviv University, Tel Aviv, Israel

3 Department of Otorhinolaryngology Head and Neck Surgery, The Chaim Sheba Medical Center, Tel Hashomer, Israel the external approach in 1904 by Totti [2]. The external approach was the favored procedure throughout the 20th century, and the endonasal approach was abandoned due to lack of adequate visualization. In 1989, McDonough and Meiring described the first modern endoscopic endonasal DCR procedure. Since then, instruments, visualization, and surgical techniques have evolved to improve endoscopic endonasal DCR (EDCR) [3-6], which has emerged as a standard method over the past decade. Moreover, the surgical success rates of EDCRs and external DCRs are now equivalent, according to the findings of several studies, and with better cosmetic results reported for EDCR [7-9].

The nasal mucosa overlying the lacrimal sac is sacrificed in the conventional EDCR. One of the modifications of the technique performed by some surgeons is the elevation of a mucosal flap prior to creating the osteotomy, and placing it over the osteotomy at the end of the procedure to avoid areas of bare bone as much as possible [10]. The commonly held belief behind this technique is that the preservation of nasal mucosal flaps can help reduce the rate of granulation 
and synechiae formation and thereby decrease the rate of failure [7]. Various techniques of mucosal flap creation have been described, including U-shaped [10], L-shaped [11], free nasal [11], and the preservation of the entire lacrimal mucosa [12].

The purpose of the current study is to compare surgical success and complication rates of EDCRs with and without mucosal flap preservation.

\section{Methods}

\section{Patients and data sources}

We performed a retrospective review of the medical records of all patients who underwent primary EDCR at the Goldschleger Eye Institute from October 2009 to October 2017. Excluded were patients who had previously undergone lacrimal surgery and those with lacrimal apparatus malignancy, posttraumatic bony deformity, and Jones tube insertion. Data on the following parameters were retrieved from the medical database and analyzed: patient demographics (age at diagnosis and gender), medical history, main optical complaint, optical examination findings, imaging findings, surgical details, postoperative success, and long-term prognosis. The study was approved by the local institutional review board (IRB) of Sheba Medical Center.

The standard preoperative evaluation for all patients included lacrimal irrigation and probing of the canaliculi with a blunt Bowman's "00" probe (Martin, Tuttlingen, Germany). The probe was inserted up to bony contact with the lacrimal sac fossa, and passage was assessed by irrigation with at least $5 \mathrm{cc}$ of saline. The patients underwent a full ophthalmologic assessment, and those with a history of nasal or sinus diseases or nasal or sinus surgeries also underwent nasal endoscopy.

Surgical success was evaluated at the end of follow-up and was defined as a complete relief of symptoms as described by the patients as well as verification of functional restoration of patent osteotomy by means of fluorescein dye clearance test, lacrimal irrigation and probing with simultaneous nasal endoscopy.

\section{Surgical technique}

All procedures were carried out by two ophthalmologists and two ear nose and throat surgeons (A.P, G.B.S and A.Y, B.S), with the patient under general anesthesia. A $30^{\circ}$ endoscope was used for the entire operation. Nasal mucosa decongestion was achieved by application of pledgets soaked in amethocaine and adrenalin. Trans-canalicular transillumination was provided by a vitrectomy light pipe in order to verify the location of the lacrimal sac. A solution of $1 \%$ lidocaine combined with 1:100 000 adrenaline was submucosally injected to the lateral nasal wall around the insertion of the middle turbinate (axilla). A semicircular incision with a radius of $1 \mathrm{~cm}$ around the axilla was performed with a sickle knife and Bellucci micro ear scissors. A posterior-based mucosal flap was then raised with a Cottle elevator to expose the lacrimal sac projection, which was folded back and covered with a piece of Gelfoam sponge (Pharmacia and Upjohn, Kalamazoo, MI, USA). The frontal process of the maxilla was removed with a $40^{\circ}$ up bite 2-mm wide Kerrison rongeur punch and a curved $15^{\circ} 3 \mathrm{~mm}$ diamond burr (Medtronic, Jacksonville, FL, USA), after which the lacrimal bone and agger nasi cell remnants were peeled off the lacrimal sac. After complete exposure of the sac, including its fundus and superior portion of the nasolacrimal duct, one of the surgeons inserted a Bowman's probe trans-canalicularly and tented the sac. Another surgeon performed a vertical incision at the anteromedial portion of the sac with the sickle knife to create a wide opening of its cavity. The incision was completed with superior and inferior horizontal incisions made with Bellucci scissors. This allowed the creation of a posteriorly based flap of the medial sac wall, which was approximated to the nasal mucosa flap. This mucosal bridge was then covered with Gelfoam, and the lacrimal system was stented with a silicone Crawford tube (Bausch \& Lomb, Shandong, China).

Postoperatively, the patients were instructed to use a saline moisturizing spray and to apply topical antibiotics (chloramphenicol drops) three times a day for 1 month. All patients were followed-up at 1, 4, and 24 weeks postsurgery and after that as needed.

\section{Statistical analysis}

An independent samples t-test was used to calculate differences in parametric variables between the two groups (Group WOF, without preservation of the mucosal flap and Group FP, with preservation of the mucosal flap). The Chisquare analysis was used to calculate proportional differences between the two groups. Data of groups with fewer than 30 patients were analyzed using nonparametric analysis tests. The overall significance level was set to an alpha of 0.05 . The statistical analysis was carried out using Microsoft Excel 16.1.1 (Microsoft Corporation, Redmond, WA, USA) and SPSS software version 23.0 (SPSS, Inc., Chicago, IL, USA).

\section{Results}

\section{Demographics and medical history}

A total of 107 patients who underwent 117 EDCR procedures were enrolled in the study. Group WOF consisted of 
51 patients (mean age \pm SD $54 \pm 17$ years, range $19-90$ years; 46 females), and Group FP consisted of 56 patients (mean age $\pm \mathrm{SD} 48 \pm 17$ years, range $16-81$ years; 40 females). Mean time of follow-up was 270 days (mean time $\pm \mathrm{SD}, 270 \pm 243,168-2701)$. The demographic characteristics and medical history of the study population are summarized in Table 1.

\section{Pre-surgical evaluation}

The most common presentation in both groups was epiphora (88.23\% in Group WOF versus $89.28 \%$ in Group FP, $P=0.193$, Chi-square). Other presentations were dacryocystitis (39.3\% in Group WOF versus $40.00 \%$ in Group FP, $P=0.937$, Chi-square) and lacrimal discharge $(29.1 \%$ in Group WOF versus $36.7 \%$ in Group FP, $P=0.388$, Chisquare). Probing and irrigation caused fluid reflux in 26 Group WOF patients and in 24 Group FP patients $(P=$ 0.318 , Chi-square), and pus reflux in 8 Group WOF patients and 6 Group FP patients $(P=0.795$, Chi-square).

Fifteen Group WOF patients and 16 Group FP patients underwent an otolaryngologic examination $(P=0.942$, Chisquare), and nasal cavity abnormalities were found in 4 and 9 patients, respectively ( $P=0.025$, Chi-square). There were no significant group differences in the numbers of referrals to preoperative imaging studies $(P=0.663$, Chi-square)

\section{Surgery}

There were 56 procedures performed in Group WOF and 61 procedures in Group FP. Ten of these 117 procedures were bilateral (five in each group, $P=0.902$, Chi-square). There were no group differences in silicone tube insertions and time until their removal $(P=0.719$ and $P=0.229$, Chisquare and $t$-test, respectively). There also were no group differences in surgical success rates $(82.1 \%$ vs. $86.8 \%$, respectively, $P=0.478$, Chi-square). Table 2 compares the surgical data between the two groups. There was no complication during the surgery or after the surgery in both groups.

\section{Discussion}

EDCR evolved over the last decade as the procedure of choice for NLDO due to its benefits compared to the common external DCR. Its advantages included no external incision or scar, no disruption of the tear pump anatomy, and the ability to visualize, diagnose, and treat endonasal pathology [13]. The disadvantages of EDCR are the need for expensive instrumentation and for the provision of meticulous hemostasis during surgery. Moreover, the learning curve of the endoscopic approach is challenging
Table 1 Demographics and medical history

\begin{tabular}{|c|c|c|c|}
\hline Variable & $\begin{array}{l}\text { WOF group } 51 \\
\text { patients }(n, \%)\end{array}$ & $\begin{array}{l}\text { FP group } 56 \\
\text { patients }(n, \%)\end{array}$ & $P$ value \\
\hline Age in years (mean) & 54.3 & 48.2 & 0.117 \\
\hline \multicolumn{4}{|l|}{ Gender } \\
\hline Male & $5(9.8)$ & $16(28.57)$ & $0.021^{*}$ \\
\hline Female & $46(90.2)$ & $40(71.42)$ & \\
\hline Hypertension & & & 0.395 \\
\hline Yes & $14(27.4)$ & $11(19.6)$ & \\
\hline No & 37 (72.6) & $45(80.4)$ & \\
\hline Diabetes mellitus & & & 0.933 \\
\hline Yes & $8(15.7)$ & 11 (19.6) & \\
\hline No & $43(84.3)$ & $45(80.4)$ & \\
\hline Smoking & & & 0.293 \\
\hline Yes & $0(0)$ & $1(1.8)$ & \\
\hline No & $51(100)$ & $55(98.2)$ & \\
\hline \multicolumn{4}{|l|}{ Rheumatic diseases } \\
\hline Yes & $0(0)$ & $0(0)$ & \\
\hline No & $51(100)$ & $56(100)$ & \\
\hline aphthalmic diseases & & & 0.469 \\
\hline Yes & $4(7.9)$ & $8(14.3)$ & \\
\hline No & $47(92.1)$ & $48(85.7)$ & \\
\hline $\begin{array}{l}{ }^{b} \text { Previous ophthalmic } \\
\text { surgeries }\end{array}$ & & & 0.685 \\
\hline Yes & 7 (13.7) & $10(17.8)$ & \\
\hline No & $44(86.3)$ & $46(82.2)$ & \\
\hline $\begin{array}{l}\text { Previous nose/sinus } \\
\text { diseases }\end{array}$ & & & 0.652 \\
\hline Yes & $5(9.8)$ & $7(12.5)$ & \\
\hline No & $46(90.2)$ & 49 (87.5) & \\
\hline
\end{tabular}

WOF Group no preservation of mucosal flap, FP Group with mucosal flap preservation

*Significant

${ }^{\mathrm{a} O p h}$ thalmic diseases (retina, cornea, glaucoma)

${ }^{\mathrm{b}}$ Ophthalmic surgeries (cataract, retina, cornea, glaucoma)

for the oculoplastic surgeon, since it is difficult and sometimes impossible to suture the adjacent flaps of the lacrimal sac and nasal mucosa [14]. These complexities led to the development of a variety of techniques that do or do not preserve the mucosal flap $[15,16]$.

We compared the EDCRs with and without preservation of the mucosal flap and demonstrated that our patients who underwent the former approach had more nasal cavity abnormalities before undergoing the surgery. The surgical success rates, however, were not influenced by their presence, and the results were essentially the same for both patient groups.

There was a gender difference between groups, but gender was reportedly not a prognostic factor for the outcome of an EDCR [17]. All the other demographic and medical 
Table 2 Surgical data

\begin{tabular}{llll}
\hline Variable & $\begin{array}{l}\text { WOF group (56 } \\
\text { cases) }(n, \%)\end{array}$ & $\begin{array}{l}\text { FP group (61 } \\
\text { cases) }(n, \%)\end{array}$ & $P$ value \\
\hline $\begin{array}{llll}\text { Eye } \\
\quad \text { Right }\end{array}$ & $30(53.6)$ & $36(59.9)$ & 0.352 \\
$\quad$ Left & $26(46.4)$ & $25(40.1)$ & \\
Lacrimal tubing & & & 0.719 \\
$\quad$ Yes & $54(96.4)$ & $58(95.0)$ & \\
$\quad$ No & $2(3.6)$ & $3(5)$ & 0.229 \\
$\begin{array}{l}\text { Stenting period } \\
\text { (weeks) }\end{array}$ & 9 & 11 & 0.478 \\
Surgical success & & & \\
$\quad$ Yes & $46(82.2)$ & $53(86.8)$ & 0.582 \\
$\quad$ No & $10(17.8)$ & $8(13.2)$ & \\
Revision surgery & 5 & 3 & \\
\hline
\end{tabular}

WOF Group no preservation of mucosal flap, FP Group with mucosal flap preservation

history data were similar for both groups and, with the exception of mucosal flap preservation, the surgical technique was the same. The surgical success rates and the number of complications after 9 months were also comparable.

There are numerous studies that examined the success rates of individual EDCRs either with or without preservation of a mucosal flap (without comparison between the techniques) $[13,15,16]$. Those who favored flap preservation claimed that the lacrimal sac mucosa allows primary intention healing and that poor or minimal preservation of mucosa may lead to increased granulation and fibrosis [18]. Those who do not support preservation of the nasal mucosa claim that the success rates are high and the operative time is shorter without it [19].

Only three studies compared flap preservation to nonpreservation EDCRs, and there was no consensus regarding the preferred method. Ji et al. reported significantly higher success rates in the mucosal flap group compared to the nonflap group [20], while Khalifa et al. and Kansu et al. did not find any differences [21, 22]. However, there was considerable variation in their surgical approaches. Ji et al. used Merocel dressing on the flap and no silicone stents (which is now known to increase the success rates) [20], while Khalifa et al. performed the surgery with the patients under local anesthesia and used tissue glue to the mucosal edges with a Gelfoam patch [21]. Kansu et al. observed that several surgeons had performed the two techniques [22].

The strengths of the current study are the large numbers of patients and the uniformity of the surgical procedure (same teams, same protocols) between the groups. The limitations of this study lie in its retrospective nature and the absence of postoperative anatomical examination findings that should be included in future studies.

\section{Conclusions}

These findings on the value of preserving the mucosal flap in EDCRs indicate that it bestows no benefits in terms of surgical success and complication rates compared to EDCRs in which the mucosal flap is removed. A randomized controlled trial with uniformity of the surgical components is warranted to validate these findings.

\section{Summary}

\section{What was known before}

The nasal mucosa is sacrificed in conventional endoscopic dacryocystorhinostomies (EDCRs).

Some surgeons, however, modify the technique by elevating a mucosal flap prior to creating the osteotomy with the aim of preserving the mucosa

\section{What this study adds}

There were no differences in surgical success or complications rates between the two procedures

No benefit for adding flap preservation to conventional EDCRs.

\section{Compliance with ethical standards}

Conflict of interest The authors declare that they have no conflict of interest.

Publisher's note Springer Nature remains neutral with regard to jurisdictional claims in published maps and institutional affiliations.

\section{References}

1. Caldwell GW. Two new operations for obstruction of the nasal duct, with preservation of the canaliculi, and with an incidental description of a new lachrymal probe. Am J Ophthalmol. 1893; 10:189-93.

2. Totti A. Nuovo Metodo conservatore dicura radicale delle suppurazione croniche del sacco lacrimale (dacricistorhinostomia). Clin Mod (Firenza). 1904;10:385

3. Cukurova I, Bulgurcu S, Arslan IB, Dikilitas B. Comparison of piezosurgery and hammer-chisel in endoscopic dacryocystorhinostomy. J Craniofac Surg. 2018;29:1612-3.

4. Selig YK, Biesman BS, Rebeiz EE. Topical application of mitomycin-C in endoscopic dacryocystorhinostomy. Am J Rhinol. 2000;14:205-7.

5. Cokkeser Y, Evereklioglu C, Tercan M, Hepsen IF. Hammerchisel technique in endoscopic dacryocystorhinostomy. Ann Otol Rhinol Laryngol. 2003;112:444-9. 
6. Ovet G, Sakarya Y, Senturk M. A comparative study of transcanalicular diode laser supported endoscopic dacryocystorhinostomy and non-laser endoscopic dacryocystorhinostomy. Am J Otolaryngol. 2016;37:497-501.

7. Cokkeser Y, Evereklioglu C, Er H. Comparative external versus endoscopic dacryocystorhinostomy: results in 115 patients (130 eyes). Otolaryngol Head Neck Surg. 2000;123:488-91.

8. Lin GC, Brook CD, Hatton MP, Metson R. Causes of dacryocystorhinostomy failure: external versus endoscopic approach. Am J Rhinol Allergy. 2017;31:181-5.

9. Ben Simon GJ, Joseph J, Lee S, Schwarcz RM, McCann JD, Goldberg RA. External versus endoscopic dacryocystorhinostomy for acquired nasolacrimal duct obstruction in a tertiary referral center. Ophthalmology. 2005;112:1463-8.

10. Tsirbas A, Wormald PJ. Endonasal dacryocystorhinostomy with mucosal flaps. Am J Ophthalmol. 2003;135:76-83.

11. Trimarchi M, Giordano Resti A, Bellini C, Forti M, Bussi M. Anastomosis of nasal mucosal and lacrimal sac flaps in endoscopic dacryocystorhinostomy. Eur Arch Otorhinolaryngol. 2009; 266:1747-52.

12. Codere F, Denton P, Corona J. Endonasal dacryocystorhinostomy: a modified technique with preservation of the nasal and lacrimal mucosa. Ophthalmic Plast Reconstr Surg. 2010;26: 161-4.

13. Marcet MM, Kuk AK, Phelps PO. Evidence-based review of surgical practices in endoscopic endonasal dacryocystorhinostomy for primary acquired nasolacrimal duct obstruction and other new indications. Curr Opin Ophthalmol. 2014;25:443-8.
14. Zilelioglu G, Tekeli O, Ugurba SH, Akiner M, Akturk T, Anadolu Y. Results of endoscopic endonasal non-laser dacryocystorhinostomy. Doc Ophthalmol. 2002;105:57-62.

15. Tsirbas A, Wormald PJ. Mechanical endonasal dacryocystorhinostomy with mucosal flaps. Otolaryngol Clin North Am. 2006;39:1019-36.

16. Green R, Gohil R, Ross P. Mucosal and lacrimal flaps for endonasal dacryocystorhinostomy: a systematic review. Clin Otolaryngol. 2017;42:514-20.

17. Mak ST, Io IY, Wong AC. Prognostic factors for outcome of endoscopic dacryocystorhinostomy in patients with primary acquired nasolacrimal duct obstruction. Graefes Arch Clin Exp Ophthalmol. 2013;251:1361-7.

18. Onerci M, Orhan M, Ogretmenoglu O, Irkec M. Long-term results and reasons for failure of intranasal endoscopic dacryocystorhinostomy. Acta Otolaryngol 2000;120:319-22.

19. Hodgson N, Bratton E, Whipple K, et al. Outcomes of endonasal dacryocystorhinostomy without mucosal flap preservation. Ophthalmic Plast Reconstr Surg. 2014;30:24-27.

20. Ji QS, Zhong JX, Tu YH, Wu WC. New mucosal flap modification for endonasal endoscopic dacryocystorhinostomy in Asians. Int J Ophthalmol. 2012;5:704-7.

21. Khalifa MA, Ragab SM, Saafan ME, El-Guindy AS. Endoscopic dacryocystorhinostomy with double posteriorly based nasal and lacrimal flaps: a prospective randomized controlled trial. Otolaryngol Head Neck Surg. 2012;147:782-7.

22. Kansu L, Aydin E, Avci S, Kal A, Gedik S. Comparison of surgical outcomes of endonasal dacryocystorhinostomy with or without mucosal flaps. Auris Nasus Larynx. 2009;36:555-9. 